\title{
Application of Cold Metal Transition Technology in Automobile
}

\section{Manufacture}

\author{
Yan Liu ${ }^{1, a}$, LiuxinZhang ${ }^{2, b}$, Yongman Chen ${ }^{2, c}$ \\ ${ }^{1}$ The Liaoning Provincial Key Laboratory of Advanced Materials \& Preparation Technology, \\ Shenyang University, Shenyang, 110044, China \\ ${ }^{2}$ School of Mechanical Engineering, Shenyang University, Shenyang 110044, China

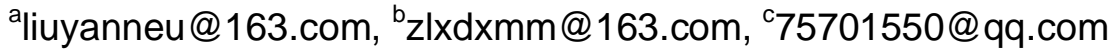

Keywords: cold metal transition technology, automobile manufacture, aluminium alloy, magnesium alloy, high-strength steel

\begin{abstract}
Based on the analysis of the characteristics of cold metal transition welding technology and the welding problems of the thin plate and dissimilar materials, this paper summarizes its applications in automobile industry. Cold metal transition technology can effectively solve the problems of burn-through and deformation of steel sheet and welding of dissimilar metals because of its characteristics of low heat input and low droplet transition temperature. The heat input controllability, coupled with the feature of the special unified expert database system of the cold metal transition technology makes it particularly suitable for automatic welding. It is commonly used in the automotive industry for the welding of aluminum alloys, magnesium alloys, high-strength steels and dissimilar metals. With the continuous upgrading of materials, the technology still needs to be continuously improved and upgraded to enrich the unified expert database system to play a better role in automobile manufacturing.
\end{abstract}

\section{Introduction}

So far, the number of cars around the world is close to 1.2 billion. The low emission and low fuel consumption of automobiles are of vital importance in the future development. Automobile lightweight is the key technology to achieve this goal, the most effective way is to reduce the weight of the material, the requirements of the welding process will be more stringent.

At present, the main three kinds of welding technology for automobile body manufacture are melting inert gas shielded welding/melting polar active gas shielded welding (MIG/MAG), resistance spot welding and laser welding. With the gradual light weight of the car and the thickness of the material need to be thinner, it is easy to weld the workpiece in the traditional MIG/MAG welding. These three kinds of welding technology are now unable to meet the needs of new materials for welding technology, we must develop and apply more advanced welding process, which will expand the use of new materials in automobiles and the development of lightweight cars.

Cold metal transition (Hereinafter CMT) is widely used in the production of automobile and auto parts suppliers because of its characteristics of no splash and low heat input. Based on the analysis of the principle and characteristics of CMT, the application and development of CMT technology in automobile manufacturing industry are summarized in this paper. 


\section{Characteristics of Cold Metal Transition Technology}

In China's automotive manufacturing industry, there are welding processes of melting inert gas shielded arc welding/melting polar active gases shielded welding (MIG/MAG), resistance spot welding and laser welding. These three kinds of welding technology are mainstream, but can not meet the higher demand on the welding technology of new materials, so it is necessary for the automotive industry to develop and apply more advanced welding technology to improve the processing of new materials [1-3].

CMT Welding Technology is a new MIG/MAG welding method developed on the basis of short circuit transition, compared with MIG/MAG welding, resistance welding, laser welding and other technologies, CMT Technology has the following three advantages:

Digital Coordination of Welding Wire Pumping and Droplet Transition Process. CMT technology is a new technology developed by the Fronius company of Austria on the basis of MIG/MAG welding technology, which combines wire feeding and droplet transfer. Under the digital control, a short-circuit signal is detected, and the information is fed back to the wire feeder. At this time, wire feeder immediately pumpback the wire to get the droplet out of the wire. The transition mode of CMT technology is completely different from the traditional method of droplet transfer, thus the weld is smooth and beautiful [4].

Low Heat Input. The short-circuit transition will be intelligently monitored by the welding system under the digital control in the welding process, when the droplet transits, the current will be instantly reduced to a very low level, so that the heat input is also reduced to a very low level, and at the same time the pumpback of solder wire are stopped. In this transition, the arc has a very short process of heat input. Compared with the ordinary MIG/MAG welding, the CMT technology's heat input is greatly reduced, so the resulting weld is more uniform and has good bridging ability, the thinnest can weld $0.3 \mathrm{~mm}$ material and arc length is stable during welding [5].

No Welding Spatter. The CMT technology controls the short-circuit state of the droplet over time, making the droplet short circuit only very small current generation. The mechanical back-pumping movement of the welding wire causes the droplet to fall off normally, compared with ordinary MIG/MAG welding method, CMT technology short-circuit transition without short-circuit bridge explosion, so no splash produced [6-7].

\section{Application of CMT Technology in Automobile Manufacture}

Now with the development of the automobile industry, high-strength steel, magnesium alloy, aluminum alloy, plastic and composite materials have become the mainstream materials, used to improve the corrosion resistance of automobile body, improve the service life of automobiles, so that the car can achieve the purpose of lightweight. However, whether the welding of aluminum alloy, magnesium alloy, high-strength steel or dissimilar metal has some problems and difficulties, it also restricts their application in automobile manufacture, which requires the development of new welding technology or equipment.

Burn-through phenomenon is the most easy to appear when the thin plate is welded. If the fused metal is subjected to a greater stress, it will produce a burning phenomenon, and once the plate is burnt, it will not be repaired. Figure 1 shows that the metal mass, volume and width of molten pool are quantitative, the change of Arc pressure $\mathrm{P}$ will determine the depth of molten pool. Welding deformation is also the most common in sheet welding. Because of its low welding heat input, CMT technology can solve welding problems such as burning and deformation of thin plate during welding. 




Fig.1 The stress state of the molten pool

Application of CMT Technology in Aluminum Alloy of Automobile Industry. Aluminum alloy is a very popular material in automobile industry because of its high specific strength, strong corrosion resistance and low recovery and reuse cost. But because the aluminum alloy resistivity is low, the thermal conductivity is high. Once using traditional resistance spot welding to weld, it requires a greater current, high energy consumption, and even causes the electrode burn seriously, remains a short life, consuming time and power. The electrode is easily polluted when the resistance spot welding is welded to the aluminum [8]. In actual production, the electrodes need to be repaired or replaced every 300 weld spots, which has a certain effect on the continuity of the actual production. Caorui et al., conducted the experiment of CMT technology for 6061 aluminum alloy steel of the point plug welding test, analyzed the welding parameters and the hole diameter of the aluminum alloy plate on the tensile load of the impact of the aluminum alloy in the automotive industry to provide a basis for the connection [9]. Beytullah Gungor et al., conducted the experiment of CMT technology, 6mm thick 5083-h111 and 6082-t651 dissimilar aluminum alloy welding research. It is found that the CMT technology can achieve high speed welding, and the joint is of good appearance and strength to meet the requirements [10]. R. Cao et al., successfully achieved $1 \mathrm{~mm}$ thick aluminum alloy and $1 \mathrm{~mm}$ thick Q235 welding using CMT technology, with 4303 wire as filler metal, heat input control in 100 200J/mm, heat-affected zone and intermetallic compound layer are very small, the strength can be comparable to the strength of the same aluminum welding [11-12].

Application of CMT Technology in High Strength Steel of Automobile Industry. The high strength steel sheet is thin, the assembly gap is not stable, once using traditional MIG/MAG welding process, workpiece will appear weld wear, deformation and other serious phenomena. Lin et al., use CMT technology to $0.6 \mathrm{~mm}$ and $1.5 \mathrm{~mm}$ thick high-strength steel sheet lap welding. The results show that the welded joint has no obvious defects in the weld formation, and the performance is superior to that of the conventional MAG welding, and the welding joint strength is fully standard [13]. Zhao Jingchi et al., use 1.5mm thick 6061 aluminum alloy and 1.82 thick DP780 galvanized steel plate for the CMT fusion brazing process test, determine the best welding parameters, so that the appearance of uniform, well formed lap joints [14].

CMT Technology with its heat input controllability characteristics, coupled with a special unified expert library system, is particularly suitable for automatic welding, whether it is for aluminum alloy, magnesium alloy, high-strength steel, or dissimilar metal welding can be completed excellently. Therefore, the application potential of CMT technology in automobile manufacturing industry is limitless. 


\section{Conclusions}

The birth of CMT technology is another innovation in the development of welding technology. CMT has perfect combination of the movement of the wire and the droplet transition, so that in the process of welding, it has a small heat input, no splash, high tolerance of assembly clearance, small deformation, uniform and beautiful weld formation, especially for the automotive industry, aluminum alloy, magnesium alloy, high-strength steel and dissimilar metal connections. CMT has been actually used in automotive production by a number of automotive companies. However, the technology is not developed for a long time. With the continuous upgrading of materials, the technology still needs to be continuously improved and upgraded to enrich the unified expert database system to play a better role in automobile manufacturing.

\section{Acknowledgments}

This work was financially supported by the Liaoning Province Natural Science Fund Project (No. 20170540643).

\section{References}

[1] Q.L.Lin, G.J.Mao and Q.Huang: Journal of Iron and Steel Research Vol. 23 (2016), p. 566-572

[2] J.Lin, N.Ma and Y.Lei: Journal of Materials Processing Technology Vol. 312 (2013), p. 1303-1310

[3] Y.B.Liu, Q.J.Sun and Y.L.Liu: Journal of Welding Vol. 35 (2014), p. 1-4.

[4] D.L.Wang, Z.X.Zhang and M.Z.Liang: Journal of Welding Vol. 35 (2014), p. 6-10

[5] X.Y.Wang, R.F.Wu and X.L.Yin: Welding Technology Vol. 3 (2014), p. 67-69

[6] R Talalaev, R Veinthal and A Laansoo: Estonian Journal of Engineering Vol. 18 (2012), p. 45-49

[7] H.T.Zhang, J.C.Feng and L. L.Hu: Materials Science \& Technology Vol. 20 (2011), p. 128-132

[8] Y.L.Chong, L.Kong and Z.Song: Journal of Welding Vol. 34 (2013), p. 71-74

[9] R.Cao, Q.Huang and H.X.Zhu: Journal of Welding Vol. 36 (2015), p. 15-18

[10]B.Gungor, E.Kaluc and E.Taban: Materials \& Design Vol. 54 (2014), p. 207-211

[11]R.Cao, Q.Huang and J.H.Chen: Journal of Alloys \& Compounds Vol. 585 (2014), p. 622-632

[12] G.P.Rajeev, M.Kamaraj and S.R.Bakshi: Journal of the Minerals Metals \& Materials Society Vol. 66 (2014), p. 1061-1067

[13]L.Li, W.Q.Wang and Q.L.Meng: Construction Machinery Technology and Management Vol. $12(2013)$, p. 91-94

[14]J.Q Zhao: Research on Microstructure and Properties of CMT Welding-Brazing of Aluminum and Steel (Jiangsu University, Zhenjiang 2016) 